the whole earth cannot be retarded exactly as though it were a rigid body. Now the tidal protuberance has not this required form, and therefore there results a slow secular distortion of the earth arising from the unequal distribution over the surface of the forces which constitute the tidal frictional couple.

The greater part of the pull which retards the rotation is applied in the equatorial regions, and therefore the rotation of those regions will be more rapidly retarded than that of the polar regions. As the earth's rotation is from west to east, it follows that the polar regions will outstrip the equator and will move very slowly from west to east relatively to the equatorial parts.

The exact mathematical solution for this kind of a distortion of a viscous spheroid shows that it consists in a simple cylindrical motion round the axis of rotation, each point moving from east to west with a linear velocity proportional to the cube of its distance from that axis.

The distortion of the surface of the globe consists of a motion in longitude from west to east, relatively to a point in the equator, the rate of change of longitude being proportional to the square of the sine of the latitude.

Numerical calculation shows, however, that in the later stages of the earth's history (the development being supposed to follow the laws found in the paper on "Precession") the distortion must have been very small. With a certain assumed viscosity it is found that, looking back $45,000,000$ years, a point in latitude $60^{\circ}$ would lie $14^{\prime}$ further east than at present. From this it follows that this cause can have had little or nothing to do with the crumpling of geological strata.

As, however, the distorting force varies inversely as the sixth power of the moon's distance, it seems possible that in the very earliest stages this cause may have had sensible effects. It is therefore noteworthy that the wrinkles raised on the surface would run north and south in the equatorial regions, with a tendency towards northeast and south-west in the northern hemisphere, and north-west and south-east in the southern one. The intensity of the distorting force at the surface varies as the square of the cosine of the latitude.

An inspection of a map of the earth shows that the continents (or large wrinkles) conform more or less to this law. But Prof. Schiaparelli's map of Mars ${ }^{1}$ is more striking than that of the earth, when viewed by the light of this theory; but there are some objections to its application to the case of Mars. If, however, there is any truth in this, then it must be postulated, that after the wrinkles were formed the crust attained sufficient local rigidity to resist the obliteration of the wrinkles, whilst the mean figure of the earth adjusted itself to the ellipticity appropriate to the slackening diurnal rotation: also, it must be supposed that the general direction of the existing continents has lasted through geological history.

The second problem considered in this paper is concerning the distribution of the heat, which would be generated by the internal friction of the tidal distortion.

It was shown in the preceding paper that a very large amount of heat might be thus generated, and it appeared at first sight as though this might serve to explain in part the observed increase of underground temperature; but the solution of a certain problem concerning the cooling of an infinite slab of rock 8,000 miles thick, in which heat is being generated according to a certain law of distribution, shows that the frictional heat could not possibly explain a rate of increase of underground temperature near the earth's surface of more than $I^{\circ}$ Fahr. in 2,600 feet.

It follows, therefore, that Sir W. Thomson's investigation of the secular cooling of the earth cannot be sensibly affected by this cause.

${ }^{2}$ Memorie della Società degli Spettroscopisti Italiani, 1878 , vol. vii.
The last part of the paper does not lead to results of interest to the general reader, as it is concerned with the part played by inertia in the tides of viscous, fluid, and elastic spheres.

\section{INDIAN METEOROLOGY"}

$\mathrm{TN}$ the article "Atmosphere" of the Encyclopadia Britannica it has been justly remarked that one of the most important steps that could be taken towards the development of the science of meteorology would be extensive series of observations from such countries as India, which offers splendid contrasts of climate at all seasons; has a surface covered at one place with the richest vegetation, and at others with vast stretches of sandy deserts, and presents extensive plateaus and sharp ascending peaks, all which conditions are indispensable for collecting the data required for the solution of the problem of atmospheric physics. In working out this problem it is necessary, owing to its extreme complexity and difficulty, to give attention, not merely to questions immediately bearing on the physics of the atmosphere, but also to climatic and other practical inquiries, which may be handled with comparative ease and which afford results that contribute indirectly but very materially to the solution of the higher problem. The publications enumerated below admirably follow up this two-fold line of inquiry, and even already several important practical and theoretical conclusions seem not far from the point of being reached by the meteorologists of India.

The "Report on the Meteorology of India" is the second Annual Report issued since the administration of the Indian Meteorological Establishment was concentrated in the Central Office at Calcutta for the whole of India including British Burmah and the Islands of the Bay. In the scheme of publication of the monthly results of the observations made at the various stations over India, we note with satisfaction that the form proposed by the Permanent Committee of the Meteorological Congress at Vienna has not been adopted in some of its more important details. Thus in Mr. Blanford's tables, instead of a general monthly mean of atmospheric pressure, the mean monthly pressure for each hour of observation is given -an essential requisite for the presentation of the data required in discussing various of the more important problems of international meteorology. Indeed these tables possess the very high merit of being, with perhaps one exception, entirely suited for the discussion of climatic questions of an international character-the single exception being the lumping together of the two or four daily observations of the winds into one monthly mean, instead of a monthly mean for each hour of observation as is so admirably carried out by Professor Rubenson in his annual reports of Swedish meteorologry.

The most interesting part of this report is that which deals with the failure of the rains in Western and Southern India which resulted, as is only too well known, in one of the most terrible and wide-spread famines of recent years. The mode of treatment is grounded on the practice adopted by the Office, in framing forecasts of coming seasons to which we have several times drawn the attention of the readers of NATURE (vol xiii. p. 66, \&c.), and which may be described as proceeding on the assumption that there is a certain persistency in meteorological conditions; that, for instance, the longer a given state of weather has lasted, the less the probability of a speedy change ; and that as regards the distributions of pressure, on which weather is so dependent, certain states of the atmosphere tend to perpetuate or reproduce themselves in the same region in such a manner as to maintain a

" "Report on the Meteorology of India in 1876 ," By Henry F. Blanford. "The Indian Meteorologist's Vade-Mecum." By Henry F. Blanford. "Indian Meteorological A emoirs;" issued under the d rection of Henry $F$. "Indian Meteorological Memoirs;" issued under the d "ection of Henry F. dency." By Charles Chambers, F.R.S. 
constant difference between the average pressure of two neighbouring regions which, though protracted, is not permanent, but disappears after a longer or shorter time. Mr. Blanford largely inclines to trace the failure of the rains to an unusually great expanse of snow covering the southern slopes of the Himalayas, much of which fell very late in the season, and which acted as a cooling agent, bringing about an abnormal distribution of pressure, and consequently of winds, temperature, and rainfall, conditions which, once fairly established, went on reproducing themselves so that cyclonic and anti-cyclonic areas of an abnormal character gained a certain persistency over those parts of India where the rainfall was deficient and where it was in excess. Should future observations confirm this hypothesis, the result will be one of the most important yet arrived at in practical meteorology.

The least satisfactory part of the report, perhaps, is that referring to the relation of rainfall to the sun-spot period, in which too much stress appears to be laid on the results of data collected from a wide geographical superficies, and too little stress upon data referring to limited regions; the data of which regions, it may be added, require for their satisfactory discussion to be examined with reference to their seasonal as well as annual yariations during the sun-spot periods.

The praciical part of the "Indian Meteorologist's Vade-Mecum" being part 1 of the work, is in many respects a model-handbook for the observers for whose use it is intended. The clearness with which the difficulties altending the making of real observations of temperature are apprehended is altogether admirable; and the prowisions and precautions as regards instruments, hours, and modes of observing actually taken are of such a nature as likely to secure observations of a high quality, owing to an increased intelligence, and efficiency on the part of the nbservers $v$ bo work in accordance with the principles and instructions laid down for their guidance.

Mr. Chambers' book is an elaborate and important work on the Meteorology of the Bombay Presidency, based on all the observations made in the Presidency dun to 1874 . Its splendid porte-folio of eighty highly finished maps and diagrams printed in colours, as well as is excellent typography with I 59 tables of results, many of them being wholly or in part laborious and elaborate analyses of the different data of observation, render the work an édition de luxe. The contributions with which this work enriches Indian meteorology are twofold, viz., the results of the hourly observations made for many years at Kurrachee, Deesa, Bombay, Poona, and Belgaum; and the monthly averages for numerous stations throughout the Presidency, from which the temperature, rainfall, and winds of this part of Asia are charted with a fulness and consequent approximation to the truth not hitherto attainable. The influence which the broad physical features of the region, such as its lofty mountain ranges, bigh plateaus, river valleys, and extensive sandy deserts, has on the climatology of the Presidency is worked out with great slill and ability. Still more able are the discussions of the hourly observations of pressure, temperature, humidity, and cloud, made at the five chief stations, rogether with many suggestive refections on the results developed, which will well repay the reader's best attention, even though he may sometimes not see his way to agree with the opinions expressed.

A healtby feature of Indian meteorology is the vigorous manner in which the making of hourly observations is pushed at many stations which have been admirably closen as respects the objects sought to be attained, and the comparatively full and prompt discussions of the resuits which are published from time to time. Of the problems handled in those discussions the most frequent as well as the most important is that of the diurnal oscil lations of the barometer. To this very difficult problem Mr. J. Eliot, for example, makes a valuable contribution in a paper on two storms in Bengal during 1876 , which were accompanied with increased atmospheric pressure, and the apparent reversal of the normal diurnal oscillation of the barometer. This reversal was found to be accompanied with an instantaneous and complete change of wind direction and a great fall of temperature, which, as they occurred before the rain began to fall, proved that they were not due merely to an inrush of a strong humid current from the Bay of Bengal. The sudden chilling of the air, accompanied as it was by an increase of pressure, also proved that the changes were not due to the internal action of a mass of air or to horizontal or surface currents from the interior, which would have been warm currents, but that they were probably produced by the downrush of a cold upper current, a conclusion which will doubtless receive further examination not only from its bearing on barometric fluctuations but also on the theory of storms.

\section{OUR BIG GUNS}

WE may leave the explanation of the disaster on board the Thunderer for the present to those who have been appointed to inquire into the matter. But in the mean time it will be well to consider what are the elements of weakness, if any, in the construction of our big guns.

The system of building up large guns by shrinking coiled iron tubes over a central steel tube seems extremely well adapted to prevent a laterai explosion; for even when the steel tube has had a lonsitudinal crack, the gun has been frequently fired without any further evil consequence.

But our guns are manifestly deficient in longitudinal strength, for the steel tube is the only tube continuous from end to end. If, then, there should be any ring-crack in the steel tube, there is little to prevent its separation into two parts beyond the friction of the coiled tubes, and the dove-tailing by which it is attempted to join the coiled cylinders together.

Now considerable longitudinal stress on the steel tube must be caused every round by the rifling necessary to give the shot its proper rotation, and occasionally, by a jamming of the shot. Also every discharge of the gun must cause a violent vibration in every part, and should the junction of the I B coil with the C coil and breechpiece work rather loose, this would be likely to cause a ring-crack in the steel tube in that neighbourhood.

When rapidly-exploding powder was used in the service the guns were very properly riffed with an increasing twist with a view to remove every possible obstruction to the initial motion of the shot. The increasing twist is still in use notwithstanding all the efforts that have been made to manufacture a powder that will burn slowly, so as to make the propeling pressure on the shot more nearly uniform. With a view to distribute the work of giving rotation to the shot uniformly along the bore, the rifling should be calculated to give a nearly constant pressure on the studs. But this depends upon the law of explosion of the powder. And this law is very variable, and very little understood. Cnly we know this - that the more nearly the force propelling the shot becomes constant, the more nearly the rifling approaches the uniform twist in order to obtain a constant pressure on the studs. Now the objection to the increasing twist is that it throws the chief part of the xork of giving rotation towards the muzzle, where the gun is weakest. Also there is a difficulty in arranging the studs on the shot, and it now appears that the increasing twist allows the shot to slip forward when the gun is depressed. It seems, therefore, desirable to revert to the uniform twist of rifling now an improved powder is used.

But in order to give the gun additional strength in direction of its length, it seems desirable that the steel 